\title{
Influence of methylphenidate treatment assumptions on cognitive function in healthy young adults in a double-blind, placebo-controlled trial
}

\author{
This article was published in the following Dove Press journal: \\ Psychology Research and Behavior Management \\ 26 August 2013 \\ Number of times this article has been viewed
}

\author{
Jean-Luc Mommaerts' \\ Gerlinde Beerens' \\ Lieve Van den Block' \\ Eric Soetens ${ }^{2}$ \\ Sandrina Schol' \\ Erwin Van De Vijver' \\ Dirk Devroey' \\ 'Department of Family Medicine, \\ ${ }^{2}$ Department of Cognitive and \\ Biological Psychology, Vrije \\ Universiteit Brussel, Belgium
}

\begin{abstract}
Background: Increasing numbers of students use stimulants such as methylphenidate (MPH) to improve their study capacity, making them prone to subsequent prolonged drug abuse. This study explored the cognitive effects of MPH in students who either assumed they received MPH or assumed they received a placebo.

Methods: In a double-blind, randomized, placebo-controlled trial with a between-subjects design, 21 students were subjected to partial sleep deprivation, receiving no more than 4 hours sleep the night before they were tested. In the morning, they were given either a placebo or $20 \mathrm{mg}$ of MPH. They then performed free recall verbal tests and Go/No-Go tasks repeatedly, their moods were evaluated using Profile of Mood States and their tiredness was assessed using a visual analog scale, with evaluation of vigilance.
\end{abstract}

Results: No significant differences were found between those subjects who received MPH and those who received a placebo. However, significant differences were found between subjects who assumed they had received MPH or had no opinion, and those who assumed they had received a placebo. At three minutes, one hour, and one day after memorizing ten lists of 20 words, those who assumed they had received MPH recalled 54\%, 58\%, and 54\% of the words, respectively, whereas those who assumed they had received placebo only recalled $35 \%, 37 \%$, and $34 \%$.

Conclusion: Healthy, partially sleep-deprived young students who assume they have received $20 \mathrm{mg}$ of MPH experience a substantial placebo effect that improves consolidation of information into long-term memory. This is independent of any pharmacologic effects of MPH, which had no significant effects on verbal memory in this study. This information may be used to dissuade students from taking stimulants such as MPH during examination periods, thus avoiding subsequent abuse and addiction.

Keywords: methylphenidate, treatment assumption, placebo, cognitive functioning

\section{Introduction}

\section{Methylphenidate}

Methylphenidate (MPH) is an amphetamine analog that increases extracellular levels of noradrenaline and dopamine in the brain by blocking their monoamine transporters. ${ }^{1}$ An increase in extracellular dopamine is thought to improve attention and motivation, and to cause a general increase in motor activity. ${ }^{1}$ Noradrenaline is believed to increase wakefulness, alertness, exploratory activity, and attention, and also has an effect on mood and blood pressure. ${ }^{1,2}$
Correspondence: Jean-Luc Mommaerts Department of Family Medicine, Vrije Universiteit Brussel, Laarbeeklaan 103, B-I090 Brussels, Belgium

Tel +32 32890400

Fax +32 32890443

Email jean.luc.mommaerts@pandora.be request permission may be found at: http://www.dovepress.com/permissions.php 
In spite of the emergence of newer drugs, MPH is still one of the most frequently used drugs in the treatment of attention deficit hyperactivity disorder (ADHD) in children and adolescents, and is recommended as first-line treatment for ADHD. ${ }^{3}$ During the last few years, there has been a significant increase in the diagnosis of ADHD and in the corresponding prescription of stimulant drugs such as MPH. ${ }^{1,4}$

Reported side effects of MPH are anorexia, nausea, vomiting, stomach ache, nervousness, headache, insomnia, and tachycardia; these effects increase linearly with the dose. Other adverse effects are motor and vocal tics. ${ }^{5,6}$

\section{Memory improvement after amphetamine use}

Several placebo-controlled studies have used free recall of word lists to examine the cognitive effects of d-amphetamine on healthy adults. These studies show that $d$-amphetamine does not influence short-term memory, ${ }^{7-10}$ but does act after initial memory encoding to improve long-term verbal memory. This improvement is prolonged by administering the drug before or during consolidation, as learned information is gradually stored into long-term memory. ${ }^{8}$

\section{Misuse of stimulants by college students}

Recent research shows that MPH misuse is increasing among college students, as is the illicit use of other stimulants normally used to treat ADHD; some studies report a 10-fold increase in the past two decades. ${ }^{6}{ }^{11}$ University students also misuse stimulants: for example, $4 \%$ of US university students misuse MPH each year. ${ }^{12}$ The motivations that university students cite most frequently for stimulant use are to heighten concentration (58\%), increase alertness (43\%), and just to "get high" (43\%). ${ }^{13}$

\section{Use of stimulants during examination periods}

Many students experience high stress levels and sleep deprivation during examination periods, which may impair their cognitive abilities. Each student handles this stress differently; sports, relaxation, vitamin supplements, tea, and coffee are all popular choices. However, a probably underestimated number of students rely on stimulant drugs such as MPH to study better, making them more prone to subsequent prolonged drug abuse. ${ }^{14}$

It is possible that MPH may have a substantial placebo effect on students; the mere thought that they have taken something to help them study may improve their cognition. It is interesting to note that, in a number of double-blind, placebo-controlled trials in various other domains, participants who assumed they had received an active treatment showed significant better outcomes than those who assumed they had received a placebo. ${ }^{15-20}$

\section{Aim of study}

There are numerous studies comparing stimulants with placebo, but far fewer in study groups without ADHD. Thereupon, only a limited number of studies have investigated the placebo effects of stimulants, and only a few of these have focused on MPH. These studies did show that the actual effectiveness of MPH did not live up to subjects' prior expectations. ${ }^{21}$ An improvement of memory was found, but no consistent evidence for other enhancing effects was uncovered ${ }^{21}$ However, the placebo effect with MPH is not well characterized, despite significant and increasing MPH use and misuse. Therefore, more studies are needed to clarify this effect. To our knowledge, no studies have examined the effect of a subject's MPH "treatment assumption", ie, whether they assume they have received MPH or a placebo, regardless of which they have actually received. The aim of this double-blind, placebo-controlled study was to investigate this treatment assumption effect by comparing the cognitive performance of healthy young students who believed they had received MPH with the performance of those who thought they had received a placebo or had no opinion. Subjects were partially sleep-deprived during the study to simulate examination period conditions.

\section{Materials and methods Subjects}

Healthy young student volunteers were recruited using posters and advertisements in the university newspaper. Participants were excluded if they suffered from diabetes mellitus, hypertension, arrhythmias, thyrotoxicosis, epilepsy, ADHD, or any other disorder that could affect their ability to concentrate, such as sleep disorders or intellectual disabilities. Other exclusion criteria were as follows: pregnancy, a history of drug abuse, prior use of psychoactive substances including MPH, a history of depression, a family history of heart problems before the age of 60 years, and familial hyperlipidemia.

In total, 21 subjects were recruited, including seven males and 14 females, of mean age $23 \pm 3$ (range 18-33) years. All these volunteers signed an informed consent document prior to participation in the trial. They were also asked to refrain from drinking any caffeinated or alcoholic beverages and to eat no more than two pieces of fruit in the 24 hours 
prior to drug administration, in order to avoid any influence on their metabolism of MPH.

\section{Study drug}

The drug dose used was $20 \mathrm{mg}$ of MPH in an immediate-release formulation. While this is twice the dose recommended for most therapeutic purposes, it is the most common dose used in earlier studies of the ability of MPH to enhance cognitive function in normal young adults. ${ }^{21-23}$ Identical, unmarked capsules were used for both the drug and the placebo; these were administered orally approximately one hour before the initial study phase of free recall testing. When administered orally, MPH is absorbed almost completely, and food has little impact on this process. In both adults and children, MPH reaches a peak concentration 1.5-2.5 hours after ingestion of a single, immediate-release dose, and has an elimination half-life of 2-3.5 hours. ${ }^{24,25}$

\section{Procedure}

A randomized, placebo-controlled design was used, and was blinded for participants, dispensers, and outcome assessors. All subjects knew prior to enrollment that they were participating in a double-blind study that used MPH. The cognitive tests used in the trial were a free recall of words, a Go/No-Go task, and a vigilance assessment. Various tests were scheduled during and immediately after the initial free recall study phase, after a one-hour delay, and after a one-day delay.

The evening before they were tested, the participants reported to the laboratory at $8: 30 \mathrm{pm}$. On arrival, they were asked to answer a questionnaire, in order to exclude anyone who had, in the previous 24 hours, consumed any caffeinated or alcoholic beverages, any psychoactive substances, or more than two pieces of fruit. They also completed a brief physical examination, which included measurement of their blood pressure and heart rate.

Trial conditions were designed to mimic an examination period, and thus included partial sleep deprivation. Subjects were told to remain awake until 2 am, and were given several popular games to act as cognitive distracters, ie, two pinball machines, one air hockey table, six Nintendo Wii ${ }^{\text {TM }}$ consoles, a poker set, a ping-pong set, Mastermind ${ }^{\mathrm{TM}}$, and Roll-It ${ }^{\mathrm{TM}}$. Participants were also told not to eat and to drink nothing but water. At $2 \mathrm{am}$, the subjects were told to go to sleep in prepared rooms. They were then awakened at 6 am, at which time they all consumed a similar breakfast of croissants, sandwiches, jam, milk, and water. Immediately after breakfast, their baseline blood pressure, heart rate, and body temperature were measured.
Approximately one hour before the start of free recall testing, participants were given either $20 \mathrm{mg}$ of MPH or a placebo by oral administration. To determine which they should receive, they were randomized by age and gender using a computer-based minimization procedure. Of the 21 participants, ten received a placebo and 11 were given MPH.

Prior to starting the study phase of the free recall test, participants were informed that they were going to be shown a series of words, which they must memorize for an unspecified memory test that they would be given at a later time. They were then shown ten lists, each containing 20 unrelated words. After seeing each list, they were given 2 minutes to write down as many words as they could remember from the list, in a test of their immediate free recall. The study phase lasted for approximately 35 minutes. After an additional 3 minutes, the participants were given 15 minutes to recall all 200 words, in a final free recall test. One hour after the end of the study phase, this test was repeated in a one-hour delay free recall (1HDFR), and was repeated again after one day (1DDFR). ${ }^{7}$

After completing the final free recall and 1HDFR, the subjects were asked what they assumed they had received, ie, a placebo, MPH, or "I don't know". As described previously, this was their "treatment assumption". The results of the final free recall and 1HDFR were not known before their treatment assumption was questioned. Only at the end of the first day, the individual results were communicated to the participants.

The Go/No-Go task was performed twice, ie, once directly after the final free recall (approximately 2.5 hours after administration of MPH or a placebo) and the second time directly after the 1HDFR (approximately 3.5 hours after administration). In both cases, each participant's blood pressure, heart rate, and body temperature were measured directly afterwards. The schematic overview of the experimental procedure is shown in Figure 1.

\section{Word lists}

For free recall testing, ten lists of 20 unrelated Dutch words were used. These were taken from a previous cognitive experiment with d-amphetamine. ${ }^{7}$ Each word had one syllable and consisted of three to five letters. The 200 words were matched in frequency, following norms developed by Uit den Boogaart. ${ }^{26}$ These words were presented in the center of a computer screen at a constant rate of 4 seconds per word. The order of the words was randomized, but the same presentation order was used for all participants. ${ }^{7}$ During testing, subjects incorrectly "recalled" words that were not 


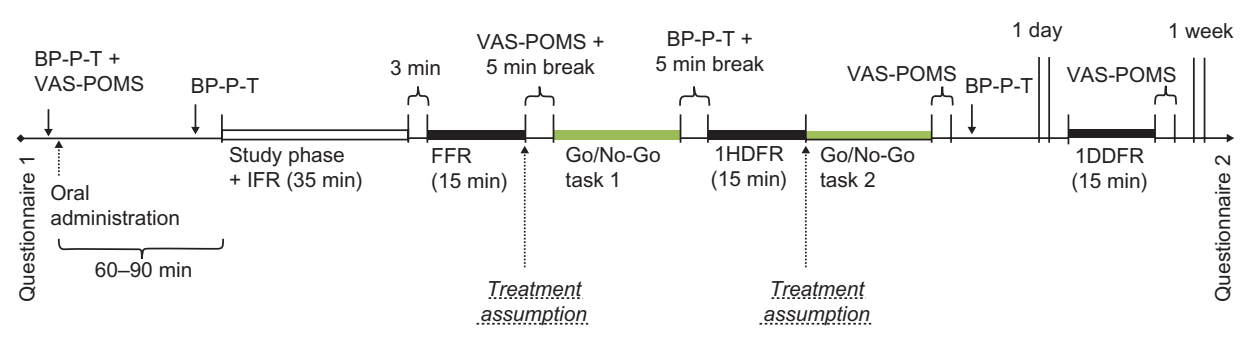

Figure I Schematic overview of the procedure of the experiment.

Abbreviations: BP-P-T, blood pressure-heart rate (pulse)-body temperature; IFR, immediate free recall; FFR, final free recall; IHDFR, one-hour delay free recall; IDDFR, one-day delay free recall; VAS, Visual Analog Scale; POMS, Profile of Mood States; MPH, methylphenidate.

actually included in any the ten-word lists. These words were counted in this study and referred to as intrusions. The short-term memory recency effect was investigated by analyzing how well subjects recalled the last five words in each word list. The long-term memory recency effect was investigated by doing the same with the first five words in each word list.

\section{Go/No-Go task}

To measure a participant's capacity for sustained attention and response control, a target-detection Go/No-Go task was replicated from earlier studies. ${ }^{23,27,28}$ Each subject was required to watch a computer screen that displayed a random series of two-digit numbers; each number was shown for 200 milliseconds and was followed by a 700 millisecond interstimulus interval. A target (Go) occurred when any number appeared twice in a row. During this task, which lasted approximately 21 minutes, one quarter of the numbers were targets. When a target (Go) appeared, the subjects were instructed to press any key on the keyboard as quickly as possible. They had to suppress this response when there was no target (No-Go). The computer registered how quickly participants responded to each Go target, from the time the target appeared until the time a key was pressed, as well as the number of correct hits. Reaction times were recorded to the nearest millisecond.

\section{Vigilance assessment}

Vigilance is the ability to maintain attention and alertness over a prolonged period of time. To assess this, the reaction times from the last 3 minutes of both Go/No-Go task runs were examined. The computer recorded these reaction times in milliseconds. ${ }^{23,29}$

\section{Subjective state tests}

The Profile of Mood States (POMS) was used to record the subjective state of each participant and a visual analog scale (VAS) was used to measure tiredness. POMS consists of
51 adjectives, which subjects must rate on a scale of 0 to 4 . These adjectives can be subdivided into the following variables: tension, depression, anger, fatigue, and vigor. ${ }^{29}$ For the VAS, a 100 millimeter horizontal line was used, anchored by the descriptors "not tired" at the left end $(0)$ and "exhausted" (100) at the right end. Subjects used this VAS to rate the question "How tired/fatigued do you feel right now?". ${ }^{30-32}$ The response value was measured in millimeters from the left end of the scale. Participants completed the POMS and VAS tests before drug administration, and at approximately 2 hours, 4 hours, and one day later.

\section{Pretest and post-test questionnaire}

When the participants arrived on the evening before testing, they were asked what they had eaten and drunk during the last 24 hours. Their weight and height were also noted, along with any sports they played and the number of hours they exercised each week. One week after the experiment, the participants were asked via email about the methods they used to memorize and recall the words in the free recall test.

\section{Ethical approval}

The ethics committee of the University Hospital of Brussels, Vrije Universiteit Brussel, approved the experimental design of this study.

\section{Statistical analysis}

To assess the influence of treatment assumption on cognitive function, the study population was divided into three main groups based on their treatment assumption: placebo (subjects who assumed they had received a placebo when asked); MPH (subjects who assumed they had received $\mathrm{MPH}$ ); and DNK (subjects who had no opinion, ie, "did not know"). A one-way analysis of variance was used to compare the participants who assumed they had taken a placebo with those who assumed they had taken MPH or said that they did not know. A criterion alpha level of 0.05 was used throughout the analyses. 


\section{Results}

\section{General results}

The protocol was completed by 21 volunteers. On arrival, none of them had a blood pressure greater than $140 / 90 \mathrm{mmHg}$ or an irregular heart rate. The characteristics of the population are shown in Table 1. No significant effects on cognition were observed between the MPH and the placebo group when comparing the immediate and delayed free recalls, Go/No-Go tasks, or vigilance tasks after administration of placebo or $20 \mathrm{mg}$ of MPH. Subjects from both study groups remembered $42 \%$ of the words during the final free recall (right after study phase) and $44 \%$ during the 1HDFR. After the final free recall, subjects from the MPH group had 221 correct hits for the Go/No-Go task compared with 231 correct hits in the placebo group $(P=0.057)$; the vigilance test also did not show any significant difference in reaction times between the groups. According to our study results, MPH does not improve consolidation into long-term memory in healthy young adults with short-term sleep deprivation. Because there was no significant difference in performance between those on MPH and those on placebo, the treatment groups were combined and the results were reanalyzed by treatment assumption.

\section{Free recall}

Table 2 shows the mean number of words that subjects recalled correctly out of 200 , depending on their treatment assumptions at final free recall and again at 1HDFR. Subjects who reported "MPH" or "DNK" after final free recall remembered significantly more words at final free recall, 1HDFR, and 1DDFR than those who reported "placebo". There were no significant differences between those who reported "MPH", "DNK" or "placebo" after 1HDFR, although the numbers still showed the same trend. These results, especially for treatment assumption after final free recall, contrast with the results from the real MPH and placebo groups, which showed no significant differences in correct word recall.

\section{Number of intrusions}

Analysis showed that treatment assumptions made no significant difference to the number of intrusions. Furthermore, there were no significant differences in intrusions between the real MPH and placebo groups.

\section{Recency and primacy effects}

Subjects recalled the last five words significantly better in the immediate free recall than in the final free recall, 1HDFR, or 1DDFR, since the words were still in short-term memory (Table 3). All applicable $P$-values were significant. In general, subjects who reported a treatment assumption of MPH or DNK recalled the last five words better than those who assumed placebo. There was, however, no difference between the real MPH and placebo groups.

The long-term memory primacy effect was studied by comparing how well subjects recalled the first five and last five words in each word list, as shown once again in Table 3. In the final free recall, 1HDFR, and 1DDFR, subjects recalled approximately twice as many of the first five words in comparison with the last five words. In most cases, subjects whose treatment assumption was MPH or DNK recalled the first five words better than those who assumed they had received a placebo. Again, there were no significant differences between the real MPH and placebo groups. Subjects reported their treatment assumptions after final free recall and again after $1 \mathrm{HDFR}$, but similar recency and primacy results were found no matter which set of treatment assumptions was used.

\section{Go/No-Go task}

Subjects performed the target detection Go/No-Go task twice, at 2.5 and 3.5 hours after administration of the drug. It should

Table I Population characteristics, correctness of assumptions, and distribution of the study population, categorized by treatment assumption

\begin{tabular}{|c|c|c|c|c|c|c|}
\hline & \multicolumn{3}{|c|}{ Treatment assumption ${ }^{a}$ after FFR $(n=2 I)$} & \multicolumn{3}{|c|}{ Treatment assumption $^{\mathrm{a}}$ after I HDFR $(\mathrm{n}=\mathbf{2 I})$} \\
\hline & Placebo $(n=12)$ & MPH $(n=4)$ & DNK $(n=5)$ & Placebo $(n=15)$ & $\mathrm{MPH}(\mathrm{n}=2)$ & DNK $(n=4)$ \\
\hline Men & 4 & 1 & 2 & 6 & I & 0 \\
\hline Women & 8 & 3 & 3 & 9 & I & 4 \\
\hline Mean age, years (SD) & $24(4)$ & $22(3)$ & $20(2)$ & $23(4)$ & $21(3)$ & $21(2)$ \\
\hline Mean weight, kg (SD) & $61(8)$ & $66(8)$ & $66(8)$ & $62(9)$ & $64(8)$ & $64(8)$ \\
\hline Treatment assumed correctly & 6 & 2 & - & 8 & $\mathrm{I}$ & - \\
\hline Treatment assumed wrongly & 6 & 2 & - & 7 & I & - \\
\hline DNK & - & - & 5 & - & - & 4 \\
\hline
\end{tabular}

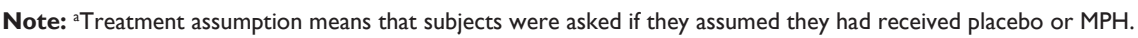

Abbreviations: MPH, methylphenidate; DNK, do not know; FFR, free recall at three minutes after study phase; IHDFR, one-hour delay free recall; SD, standard deviation. 
Table 2 Number of correctly recalled words categorized by treatment assumption after FFR, treatment assumption after IHDFR, and actual treatment

\begin{tabular}{|c|c|c|c|c|c|c|c|c|}
\hline & \multicolumn{4}{|c|}{ Treatment assumption after $F R^{a}(n=2 I)$} & \multicolumn{4}{|c|}{ Treatment assumption after IHDFR $(n=2 I)$} \\
\hline & $\begin{array}{l}\text { Placebo } \\
(n=12)\end{array}$ & $\begin{array}{l}\text { MPH } \\
(n=4)\end{array}$ & $\begin{array}{l}\text { DNK } \\
(n=5)\end{array}$ & ANOVA & $\begin{array}{l}\text { Placebo } \\
(n=15)\end{array}$ & $\begin{array}{l}\text { MPH } \\
(n=2)\end{array}$ & $\begin{array}{l}\text { DNK } \\
(n=4)\end{array}$ & ANOVA \\
\hline \multicolumn{9}{|c|}{ Mean number of correctly recalled words } \\
\hline IFR (SD) & III (24) & $140(35)$ & $130(19)$ & $\begin{array}{l}P(2)>0.05 \\
P^{*}>0.05 \\
P * *>0.05\end{array}$ & $117(26)$ & $132(24)$ & $|3|(35)$ & $\begin{array}{l}P(2)>0.05 \\
P^{*}>0.05 \\
P^{* *}>0.05\end{array}$ \\
\hline FFR (SD) & $70(21)$ & $108(32)$ & $100(22)$ & $\begin{array}{l}P(2)=0.01 \\
P^{*}=0.015 \\
P * *=0.018\end{array}$ & $78(26)$ & $99(22)$ & $102(34)$ & $\begin{array}{l}P(2)>0.05 \\
P^{*}>0.05 \\
P^{* *}>0.05\end{array}$ \\
\hline IHDFR (SD) & $73(22)$ & $115(3 \mid)$ & $103(24)$ & $\begin{array}{l}P(2)=0.01 \\
P^{*}=0.009 \\
P * *=0.025\end{array}$ & $80(26)$ & $103(17)$ & $110(37)$ & $\begin{array}{l}P(2)>0.05 \\
P^{*}>0.05 \\
P^{* *}>0.05\end{array}$ \\
\hline IDDFR (SD) & $67(24)$ & $107(35)$ & $108(17)$ & $\begin{array}{l}P(2)<0.01 \\
P *=0.021 \\
P * *=0.004\end{array}$ & $76(29)$ & $98(28)$ & $109(32)$ & $\begin{array}{l}P(2)>0.05 \\
P^{*}>0.05 \\
P^{* *}>0.05\end{array}$ \\
\hline
\end{tabular}

Notes: $P *, P$-value comparing placebo with $\mathrm{MPH} ; P^{* *}, P$-value comparing placebo with $\mathrm{DNK} ; P(2)=P$-value comparing placebo, $\mathrm{MPH}$, and $\mathrm{DNK}$ with two degrees of freedom.

Abbreviations: ANOVA, analysis of variance; SD, standard deviation; IFR, immediate free recall; MPH, methylphenidate; DNK, do not know; FFR, free recall at three minutes after study phase; IHDFR, one-hour delay free recall; IDDFR, one-day delay free recall.

Table 3 Effects of recency and primacy, categorized by treatment assumption

\begin{tabular}{|c|c|c|c|c|c|c|c|c|}
\hline & \multicolumn{4}{|c|}{ Treatment assumption after FFR $(n=2 I)$} & \multicolumn{4}{|c|}{ Treatment assumption after IHDFR $(n=2 I)$} \\
\hline & $\begin{array}{l}\text { Placebo } \\
(n=12)\end{array}$ & $\begin{array}{l}\text { MPH } \\
(n=4)\end{array}$ & $\begin{array}{l}\text { DNK } \\
(n=5)\end{array}$ & ANOVA & $\begin{array}{l}\text { Placebo } \\
(n=15)\end{array}$ & $\begin{array}{l}\text { MPH } \\
(n=2)\end{array}$ & $\begin{array}{l}\text { DNK } \\
(n=4)\end{array}$ & ANOVA \\
\hline \multicolumn{9}{|l|}{ IFR } \\
\hline \multirow[t]{3}{*}{ First 5 words recall \% (SD) } & $68(6)$ & $81(6)$ & $75(6)$ & $P(2)<0.01$ & $70(6)$ & $77(6)$ & $75(8)$ & $P(2)>0.05$ \\
\hline & & & & $P^{*}=0.002$ & & & & $P^{*}>0.05$ \\
\hline & & & & $P * *=0.045$ & & & & $p^{* *}>0.05$ \\
\hline \multirow[t]{3}{*}{ Last 5 words recall \% (SD) } & $58(6)$ & $7 \mid(10)$ & $72(3)$ & $P(2)<0.01$ & $61(7)$ & $62(11)$ & $74(6)$ & $P(2)=0.015$ \\
\hline & & & & $P^{*}=0.007$ & & & & $p^{*}>0.05$ \\
\hline & & & & $P * *<0.001$ & & & & $p^{* *}=0.004$ \\
\hline \multicolumn{9}{|l|}{ FFR } \\
\hline \multirow[t]{3}{*}{ First 5 words recall \% (SD) } & $47(8)$ & $65(8)$ & $60(8)$ & $P(2)<0.01$ & $51(8)$ & $58(10)$ & $59(9)$ & $P(2)>0.05$ \\
\hline & & & & $P^{*}=0.002$ & & & & $P^{*}>0.05$ \\
\hline & & & & $P * *=0.008$ & & & & $p^{* *}>0.05$ \\
\hline \multirow[t]{3}{*}{ Last 5 words recall \% (SD) } & $22(4)$ & $42(7)$ & $44(3)$ & $P(2)<0.0 \mathrm{I}$ & $27(6)$ & $38(7)$ & $44(6)$ & $P(2)<0.0$ I \\
\hline & & & & $P^{*}<0.00 \mathrm{I}$ & & & & $p^{*}=0.029$ \\
\hline & & & & $P * *<0.001$ & & & & $P * *<0.001$ \\
\hline \multicolumn{9}{|l|}{ IHDFR } \\
\hline \multirow[t]{3}{*}{ First 5 words recall \% (SD) } & $50(8)$ & $76(7)$ & $65(8)$ & $P(2)<0.0 \mathrm{I}$ & $54(9)$ & $69(8)$ & $68(10)$ & $P(2)=0.016$ \\
\hline & & & & $P^{*}<0.001$ & & & & $p^{*}=0.041$ \\
\hline & & & & $P * *=0.003$ & & & & $P^{* *}=0.015$ \\
\hline \multirow[t]{3}{*}{ Last 5 words recall \% (SD) } & $24(4)$ & $45(6)$ & $46(5)$ & $P(2)<0.0 \mathrm{I}$ & $28(6)$ & $39(4)$ & $47(7)$ & $P(2)<0.0$ I \\
\hline & & & & $P^{*}<0.00 \mathrm{I}$ & & & & $p^{*}=0.025$ \\
\hline & & & & $P * *<0.001$ & & & & $P * *<0.001$ \\
\hline \multicolumn{9}{|l|}{ IDDFR } \\
\hline \multirow[t]{3}{*}{ First 5 words recall \% (SD) } & $47(9)$ & 7I (8) & $66(6)$ & $P(2)<0.01$ & $52(10)$ & $67(12)$ & $65(6)$ & $P(2)=0.028$ \\
\hline & & & & $P^{*}<0.00 \mathrm{I}$ & & & & $P^{*}<0.00 \mathrm{I}$ \\
\hline & & & & $P * *<0.001$ & & & & $P^{* *}<0.001$ \\
\hline \multirow[t]{3}{*}{ Last 5 words recall \% (SD) } & $23(5)$ & $41(9)$ & $48(2)$ & $P(2)<0.01$ & $28(7)$ & $32(8)$ & $49(6)$ & $P(2)<0.0$ I \\
\hline & & & & $P^{*}=0.068$ & & & & $P^{*}>0.05$ \\
\hline & & & & $P * *=0.025$ & & & & $p^{* *}<0.001$ \\
\hline
\end{tabular}

Notes: $P(2), P$-value comparing placebo, MPH, and DNK with two degrees of freedom; $P *, P$-value comparing placebo with $M P H ; P^{* *}, P$-value comparing placebo with $D$ NK. Abbreviations: ANOVA, analysis of variance; SD, standard deviation; MPH, methylphenidate; DNK, do not know; FFR, free recall at three minutes after study phase; IHDFR, one-hour delay free recall; NS, not significant. 
be noted that the results from two subjects (a man and a woman) were excluded, due to an error in data recording. During this 21-minute task, the drug did not influence the outcome. The real MPH and placebo groups performed similarly, registering 221 and 231 hits, respectively, in the Go/No-Go task that was performed after 2.5 hours; the corresponding reaction times were 347 and 345 milliseconds. Treatment assumption also made no significant difference.

\section{Vigilance assessment}

The reaction times from the last 3 minutes of both Go/No-Go tasks were used to evaluate vigilance. Results from two subjects were excluded, as in the Go/No-Go task. In the second Go/No-Go task, subjects whose treatment assumption after final free recall was DNK were on average 69 milliseconds slower than those who assumed placebo $(P=0.02)$; this was not expected. There was no significant difference between those who assumed they had received placebo after final free recall and those who assumed MPH. No significant differences were found between the real MPH and placebo groups.

\section{Subjective responses}

The POMS results showed an alteration in subjective mood the day after administration. Participants whose treatment assumption after final free recall was MPH showed significantly more anger $(P=0.031)$ and fatigue $(P=0.036)$ than those who answered placebo. This was not seen using the second set of treatment assumptions reported after 1HDFR. The VAS scale, which measured fatigue, was not affected by assumed treatment. Again, no significant differences were found between the real MPH and placebo groups.

\section{Accuracy of treatment assumption}

Only two people (18\%) who had received MPH guessed correctly after final free recall; this declined to one person (9\%) after 1HDFR. Of the subjects who received a placebo, $60 \%$ guessed correctly after final free recall; this rose to $80 \%$ after 1HDFR. Subjects who received the active drug were almost three times less accurate in their guesses after final free recall than those who received the placebo, and they were six times less accurate after 1HDFR. Subjects who said they did not know what they had received were not taken into account (Table 1).

\section{Post-test questionnaire}

Of the 21 subjects, 20 answered all the questions, and one subject did not respond and was excluded from the analysis.
Of these 20, $14(70 \%)$ said that they had relied on their physical signs to determine whether they had received MPH or a placebo. Two participants (10\%) said they had relied on the results they expected on the immediate free recall and final free recall to guess whether or not they had taken the drug. Four $(20 \%)$ said they had relied on both their physical signs and their expected results.

\section{Discussion}

This double-blind study was designed to explore whether the assumption that they received MPH or a placebo had an effect on cognition in healthy young adults. It explicitly investigated whether MPH and/or the assumption of having taken MPH had a facilitating effect on memory consolidation processes and reaction times under the short-term sleep deprivation conditions typically associated with an examination period. To the best of our knowledge, this is the first study that has examined the effects of MPH treatment assumptions in healthy volunteers.

\section{Interpretation of results}

The effect of the treatment assumption reported by participants directly after final free recall was significant. Participants who assumed they had received MPH or who had no opinion recalled more words than those who assumed they had received a placebo. At the same time, there was no significant difference in word recall between those who really received MPH and those who did not, either on this test or on any of the other tests. Therefore, the enhanced word recall was due to differences in the subjects' treatment assumptions, and not to the drug that they took.

Several studies have shown that MPH can have an effect on mood arousal. ${ }^{33,34}$ In the present study, the assumption that they had taken MPH had a noticeable impact on subjects' anger and fatigue levels 24 hours after administration, whereas the actual treatment taken had no effect.

Participants in double-blind, randomized, placebocontrolled trials can experience treatment effects that lead to unblinding. ${ }^{19}$ For example, headaches caused by calcium channel blockers can make some participants suspect that they received the active study drug. The present study shows that assessing participants' treatment assumptions in a randomized controlled trial can also yield important information when it is not immediately evident that participants have been unblinded by treatment effects or side effects. ${ }^{19}$

Subjects who performed more confidently on the free recall tests in this study might have assumed subsequently that they had received MPH rather than a placebo; this 
possibility was addressed to a certain extent by the post-test questionnaire. It might also have been valuable to ask subjects about their treatment assumptions prior to final free recall, and to assess how confident participants felt about their performances in the free recall tests. However, given that this study showed that actual administration of MPH did not have a significant effect on free recall test results or generate any physical signs, it follows that administration of MPH did not unblind the participants. The fact that some subjects said in the post-test questionnaire that they had relied on physical signs or expected results to guess their treatment is compatible with post-test rationalization.

\section{Study limitations}

Some caution is in order when interpreting the findings of this research. This study has a between-subjects design in which participants were given either a placebo or MPH. A counterbalanced within-subject design with a oneweek washout period might have been preferable because it could have reduced the effect of differences between individuals. However, this was not possible due to resource constraints. Because of recruitment problems, there were only 21 volunteers in the study. Therefore, findings that were not statistically significant may have been so due to a small sample size. Tests were repeated several times using the same material, including during and immediately after the free recall study phase and several times later on. Therefore, it could be argued that the observed effects were partially caused by influences on the memory retrieval process. This was also noted by Zeeuws et al ${ }^{7,8,10}$ and Soetens et al. ${ }^{9}$ In their study, the use of immediate recall tests did not affect the influence of $\mathrm{d}$-amphetamine on delayed recall. ${ }^{10}$ Because of the similar activity of MPH and d-amphetamine, it can be argued that this is likely to be true for MPH as well. One should also keep in mind that intersubject variability exists with MPH. It is rapidly and extensively absorbed after oral administration, and differences in metabolism as well as pharmacodynamic drug interactions can induce differences in bioavailability, as can nutrition effects, such as high or low fat diets and associated gastric emptying times. ${ }^{1,35}$

Subjects were not forced to choose a treatment assumption. With hindsight, it would have been better to let subjects choose between MPH, placebo, and DNK, and then force them to choose between the first two. This should probably be the case in all studies which solicit treatment assumptions. Finally, a possible explanation for the lack of difference between MPH and placebo might be that the dose was too low. Alternatively, the tests used may not be particularly good tests of MPH effects in the study population.

\section{Future research}

Repeating the above study using sequential dosing of MPH or placebo would be an interesting and useful future line of research. The results of this study might lead one to conclude that students who assumed they had taken MPH during an examination period would experience more memory enhancement than those who actually took MPH. "Treatment assumption" is closely related to the placebo effect, which is thought to be associated with a spectrum of factors, including expectancy, hope, conditioning, and anxiety reduction. ${ }^{36}$ Nonblinded studies comparing placebos with no treatment options may contribute to a better appreciation of the full effect of placebos. ${ }^{37}$ Additional research with a larger study population is needed to elucidate better the precise nature of "treatment assumption". Future trials with longer follow-up and larger study populations may also clarify the effects of MPH treatment assumption in healthy subjects, especially when combined with an understanding of subjects' prior expectations about treatment efficacy.

\section{Conclusion}

This study showed that the assumption of having received a single $20 \mathrm{mg}$ dose of MPH may induce a substantial placebo effect in healthy young students, improving consolidation of information into long-term memory. Students who thought they were given the drug recalled $54 \%-58 \%$ of the word lists, while those who thought they had received the placebo recalled only $34 \%-37 \%$. This is independent of any pharmacologic effects of MPH, which in this study had no significant effects on verbal memory. This information may be used to dissuade students from taking stimulants such as MPH during their examination periods, thus avoiding one trap towards becoming addicted subsequently. ${ }^{38,39}$ In addition to this, pointing towards the placebo effect indicates to students that they have the psychologic means within themselves to enhance their own study capacity without any need for drugs.

\section{Acknowledgments}

The authors thank B Bronselaer for her contribution to identifying the tests in this study, D Proot for searching for participants and providing linguistic advice, H Verdoodt and B Driesen for reading the first versions of this manuscript, J Tack, B Ressler, and the collaborators of "Ook getest op 
mensen" for logistic support, R Buysschaert and V Beckers for examining the participants, and S Sarre for blinding of the study drugs. Last but not least, we would like to thank all the study participants.

\section{Disclosure}

The authors report no conflicts of interest in this work.

\section{References}

1. Rang HP, Dale MM, Ritter JM, Flower RJ. Rang and Dale's Pharmacology. Philadelphia, PA: Elsevier; 2008.

2. Volkow ND, Swanson JM. Variables that affect the clinical use and abuse of methylphenidate in the treatment of ADHD. Am J Psychiatry. 2003;160(11):1909-1918.

3. De Sousa A, Kalra G. Drug therapy of attention deficit hyperactivity disorder: current trends. Mens Sana Monogr. 2012;10(1):45-69.

4. Setlik J, Bond GR, Ho M. Adolescent prescription ADHD medication abuse is rising along with prescriptions for these medications. Pediatrics. 2009;124(3):875-880.

5. Heal DJ, Pierce DM. Methylphenidate and its isomers: their role in the treatment of attention-deficit hyperactivity disorder using a transdermal delivery system. CNS Drugs. 2006;20(9):713-738.

6. Klein-Schwartz W. Abuse and toxicity of methylphenidate. Curr Opin Pediatr. 2002;14(2):219-223.

7. Zeeuws I, Soetens E. Verbal memory performance improved via an acute administration of D-amphetamine. Hum Psychopharmacol. 2007;22(5):279-287.

8. Zeeuws, I, Deroost N, Soetens E. Effect of an acute d-amphetamine administration on context information memory in healthy volunteers: evidence from a source memory task. Hum Psychopharmacol. 2010;25(4):326-334.

9. Soetens E, Casaer S, D'Hooge R, Hueting JE. Effect of amphetamine on long-term retention of verbal material. Psychopharmacology (Berl). 1995;119(2):155-162.

10. Zeeuws I, Deroost N, Soetens E. Verbal memory improved by D-amphetamine: influence of the testing effect. Hum Psychopharmacol. 2010;25(5):377-387.

11. Wilens TE, Adler LA, Adams J, et al. Misuse and diversion of stimulants prescribed for ADHD: a systematic review of the literature. $J$ Am Acad Child Adolesc Psychiatry. 2008;47(1):21-31.

12. Bogle KE, Smith BH. Illicit methylphenidate use: a review of prevalence, availability, pharmacology, and consequences. Curr Drug Abuse Rev. 2009;2(2):157-176.

13. Teter CJ, McCabe SE, Cranford JA, Boyd CJ, Guthrie SK. Prevalence and motives for illicit use of prescription stimulants in an undergraduate student sample. J Am Coll Health. 2005;53(6):253-262.

14. Barrett SP, Darredeau C, Bordy LE, Pihl RO. Characteristics of methylphenidate misuse in a university student sample. Can J Psychiatry. 2005;50(8):457-461.

15. Lewis TL, Karlowski TR, Kapikian AZ, et al. A controlled clinical trial of ascorbic acid for the common cold. Ann N Y Acad Sci. 1975;258: 505-512.

16. McRae C, Cherin E, Yamazaki TG, et al. Effects of perceived treatment on quality of life and medical outcomes in a double-blind placebo surgery trial. Arch Gen Psychiatry. 2004;61(4):412-420.

17. Bausell R, Lao L, Bergman S, Lee WL, Berman BM. Is acupuncture analgesia an expectancy effect? Preliminary evidence based on participants' perceived assignments in two placebo-controlled trials. Eval Health Prof. 2005;28(1):9-26.

18. Dar R, Stronguin F, Etter JF. Assigned versus perceived placebo effects in nicotine replacement therapy for smoking reduction in Swiss smokers. J Consult Clin Psychol. 2005;73(2):350-353.
19. Colagiuri B, Morley KC, Boakes RA, Haber PS. Expectancy in double-blind placebo-controlled trials: an example from alcohol dependence. Psychother Psychosom. 2009;78(3):167-171.

20. Thomas JL, Guo H, Lynam IM, et al. The impact of perceived treatment assignment on smoking cessation outcomes among African-American smokers. J Gen Intern Med. 2008;23(9):1361-1366.

21. Repantis D, Schlattmann P, Laisney O, Heuser I. Modafinil and methylphenidate for neuroenhancement in healthy individuals: a systematic review. Pharmacol Res. 2010;62(3):187-206.

22. Volkow ND, Fowler JS, Wang GJ, et al. Methylphenidate decreased the amount of glucose needed by the brain to perform a cognitive task. PLoS One. 16 2008;3(4):e2017.

23. Camp-Bruno JA, Herting RL. Cognitive effects of milacemide and methylphenidate in healthy young adults. Psychopharmacology (Berl). 1994;115(1-2):46-52.

24. Sachdev PS, Trollor JN. How high a dose of stimulant medication in adult attention deficit hyperactivity disorder? Aust N Z J Psychiatry. 2000;34(4):645-650.

25. Kowalik S, Minami H, Silva R. Dexmethylphenidate extended-release capsules for the treatment of attention deficit hyperactivity disorder. Expert Opin Pharmacother. 2006;7(18):2547-2557.

26. Uit den Boogaart PC. Woordfrequenties in Geschreven en Gesproken Nederlands. [Word frequencies in written and spoken Dutch]. Utrecht, The Netherlands: Oosthoek, Scheltema and Holkema; 1975. Dutch.

27. Fillmore MT, Blackburn JS, Harrison EL. Acute disinhibiting effects of alcohol as a factor in risky driving behavior. Drug Alcohol Depend. 2008;95(1-2):97-106.

28. Ostling EW, Fillmore MT. Tolerance to the impairing effects of alcohol on the inhibition and activation of behavior. Psychopharmacology (Berl). 2010;212(4):465-473.

29. Childs E, de Wit H. Subjective, behavioral, and physiological effects of acute caffeine in light, nondependent caffeine users. Psychopharmacology (Berl). 2006;185(4):514-523.

30. Insana SP, Montgomery-Downs HE. Maternal postpartum sleepiness and fatigue: associations with objectively measured sleep variables. J Psychosom Res. 2010;69(5):467-473.

31. Wilhelm B, Kellert R, Schnell R, Lüdtke H, Petrini O. Lack of sedative effects after vespertine intake of oxazepam as hypnotic in healthy volunteers. Psychopharmacology (Berl). 2009;205(4):679-688.

32. Elliott R, Sahakian BJ, Matthews K, Bannerjea A, Rimmer J, Robbins TW. Effects of methylphenidate on spatial working memory and planning in healthy young adults. Psychopharmacology (Berl). 1997;131(2):196-206.

33. Hermens DF, Cooper NJ, Clark CR, Debrota D, Clarke SD, Williams LM. An integrative approach to determine the best behavioral and biological markers of methylphenidate. J Integr Neurosci. 2007;6(1):105-140.

34. Elliott WJ. Drug interactions and drugs that affect blood pressure. J Clin Hypertens (Greenwich). 2006;8(10):731-737.

35. Schlösser R, Nenadic I, Wagner G, Zysset S, Koch K, Sauer H. Dopaminergic modulation of brain systems subserving decision making under uncertainty: a study with fMRI and methylphenidate challenge. Synapse. 2009;63(5):429-442.

36. Mommaerts JL, Devroey D. The placebo effect: how the subconscious fits in. Perspect Biol Med. 2012;55(1):43-58.

37. Hróbjartsson A, Kaptchuk TJ, Miller FG. Placebo effect studies are susceptible to response bias and to other types of biases. J Clin Epidemiol. 2011;64(11):1223-1229.

38. [No authors listed]. Methylphenidate: abuse in Europe. Prescrire Int. 2013;22(135):47.

39. Tagaya H. Methylphenidate: pharmacology, indication and potential of abuse. Nihon Rinsho. 2010;68(8):1550-1555. Japanese. 


\section{Publish your work in this journal}

Psychology Research and Behavior Management is an international, peerreviewed, open access journal focusing on the science of psychology and its application in behavior management to develop improved outcomes in the clinical, educational, sports and business arenas. Specific topics covered include: Neuroscience, memory \& decision making; Behavior modification \& management; Clinical applications; Business \& sports performance management; Social and developmental studies; Animal studies. The manuscript management system is completely online and includes a quick and fair peer-review system. Visit http://www.dovepress. com/testimonials.php to read real quotes from published authors.

Submit your manuscript here: http://www.dovepress.com/psychology-research-and-behavior-management-journal 